\section{Ropas que importan. Utilizando el Upcycling como intervención en el sistema de la Moda e Indumentaria para transicionar hacia futuros sostenibles}

Alexandra Louise Vinlove ${ }^{(1)}$

\begin{abstract}
En la actualidad se desenvuelve una creciente búsqueda de incorporar prácticas sostenibles al diseño de moda e indumentaria, generalmente situando el foco en la materialidad y los procesos productivos, desde la utilización de fibras cuya producción tiene menor impacto ambiental, a la optimización de procesos de lavado, teñido y acabado, así como también la implementación de sistemas de reciclaje. Esto se debe a que "los materiales son usualmente el punto de partida por el cual la moda puede contribuir a la sostenibilidad. Son artículos de valor para agricultores, diseñadores, productores, consumidores y recicladores" (Fletcher, 2014: 21). Sin embargo, diseñar intervenciones focalizadas únicamente en crear mejoras en los procesos de producción de las prendas -aún con la intención de utilizar menos recursos y/o disminuir su impacto-, no es suficiente para tomar distancia del enfoque reduccionista, imposibilitando establecer un cambio de paradigma en el funcionamiento de la moda como industria y como agente cultural. Si se entiende a la industria de la moda como un sistema complejo, donde intervienen múltiples actores con diversas culturas, comportamientos, intereses y aspiraciones, se podrá incorporar una amplia gama de perspectivas en la resolución de problemas, con la finalidad de impulsar cambios significativos y perdurables para garantizar la transición de la industria hacia una con perspectiva sostenible en lo ético y en lo ambiental.

En este artículo se analizarán las metodologías del Upcycling como estrategia de economía circular capaz de intervenir en el funcionamiento de los circuitos de producción y consumo tradicionales, con la finalidad de generar un cambio de modelo de negocios en la industria del Diseño de Moda e Indumentaria para transicionar hacia un futuro sostenible. Se considera que estas técnicas tienen el potencial de generar puentes con las prácticas de sostenibilidad, al incentivar un acercamiento a lo local y al sentido de comunidad, apoyado por la generación de identidad e inclusión a través de la personalización y customización de la indumentaria. En esta aproximación se considerará a la indumentaria vinculada a la lista de necesidades y satisfactores de Max-Neef (1991).

Se trabajará sobre estos puntos realizando un mapeo de Wicked Problem (Rittel y Webber, 1973) sobre la obsolescencia programada en los ciclos de producción tradicionales considerando en el análisis y de manera general, aplicable a cualquier marca estándar de fast fashion y las conductas de consumo generales asociadas a este tipo de productos y marcas del mercado, tomando como base la consulta de datos de una marca líder de ventas online de indumentaria de tipo streetwear. No se hace necesario mencionar el nombre de la marca en cuestión, ya que la idea es que sus datos sirvan para contextualizar las problemáticas que se desenvuelven dentro de la industria de la moda e indumentaria en la actualidad,
\end{abstract}


haciendo foco en la posible intervención dentro del sistema a través de las metodologías del Upcycling de reparación y reutilización. A partir de esta aproximación, se identificará una posible intervención vinculada con los puntos de apalancamiento establecidos por Donella Meadows (1997) y sus impactos en los estilos de vida, situándolo bajo la lente del Diseño para la Transición (Irwin, Kossoff y Tonkinwise, 2015).

Palabras clave: Diseño de Moda e Indumentaria - Upcycling - Moda sostenible - Sostenibilidad - Inclusividad - Accesibilidad - Estilos de vida - Diseño para la Transición - Leverage points - Wicked Problem.

[Resúmenes en inglés y portugués en las páginas 127-129]

(1) Alexandra Louise Vinlove es Técnica en Diseño de Moda e Indumentaria graduada de la Asociación Biblioteca de Mujeres y Licenciada en Diseño de la Universidad de Palermo. Ejerce como diseñadora independiente con especialización en diseño sostenible, habiendo presentado algunos de sus trabajos en la muestra estática titulada Camino a la sustentabilidad, exhibida para BA Moda 2019, Buenos Aires Ciudad (CMD). En Julio de 2019 se presentó como expositora en el XIV Encuentro Latinoamericano de Diseño (Universidad de Palermo), dictando una conferencia titulada Revestir: Fashion Upcycling. Ademas, participó en la Comisión Diseño en Perspectiva dentro del IV Coloquio de Investigación y Desarrollo en Diseño Latino (2019) y en el V Coloquio Virtual Internacional de Investigadores en Diseño (2020). Actualmente se desempeña como Asistente Académica en la materia Diseño IV, perteneciente a la carrera Maestría en Gestión del Diseño (UP), dictada por la Doctoranda Daniela Di Bella. allyvinlovedesign@gmail.com

En la actualidad de la cultura occidental, la moda e indumentaria se asocia directa e inseparablemente al consumo, al materialismo y en la mayoría de las veces, a la superficialidad de la imagen, asociada a los ideales de belleza que se encuentran en constante cambio dentro de la modernidad líquida (Bauman, 2000). Estas alteraciones se aceleran dentro del marco de la sociedad del consumo y la sociedad digital (Vizcarra y Ovalle, 2011), ya que según D’Ortenzio:

El diseño actualmente se encuentra frente a una sociedad que se pregunta cómo manejar lo que ve y se le presenta desde lo individual, y se plantea cómo aprehender, dentro de la lógica del hiperconsumo los distintos elementos (tanto objetos como cuerpos) que hoy se construyen y deconstruyen deviniendo en signos y símbolos en una compleja espiral dinámica (D’Ortenzio, 2020:126).

Se verifica un cambio en los valores debido a las influencias de la rápida proliferación de las tecnologías de la comunicación y la información que intervienen en todas las esferas 
de las relaciones sociales. Según cita Di Bella (2020) una investigación de Guy Julier define a la cultura del diseño, como un fenómeno global:

En la actualidad está representado y descripto bajo una gama variada de niveles, siendo uno de los centrales el que lo ubica como foco del ocio y el consumo, y por tal se ha convertido en un entretenimiento público. Pocas industrias de Occidente han crecido en términos de presencia económica e intercambio cultural como lo ha hecho el diseño en las últimas décadas, siendo las actividades de branding y la construcción de valores-signo de las marcas, las que re-configuraron el rol y estado de la publicidad y de la comunicación, convirtiéndolo en una disciplina con un alto poder persuasivo (Guy Julier 2010, en Di Bella, 2020: 97).

Si bien cada vez se crean más iniciativas para disminuir los impactos de la industria sobre los recursos naturales, por lo general desde el diseño de indumentaria y el sistema de la moda, se sitúa el foco de estos esfuerzos sobre el uso material de fibras y los textiles, ya que resulta una tarea más fácil de abordar al concentrarse en reemplazar los materiales que se consideran nocivos por otros cuya elaboración resulta menos perjudicial, sin la necesidad de cuestionar los ritmos de producción y consumo establecidos a nivel sistémico, siendo que según afirma Fletcher:

El desafío es pensar más allá de los materiales para promover cambios, creando eslabones entre las fibras y su ciclo de vida, los materiales y sus usuarios, y entre la industria y los sistemas culturales y ecológicos que la sostienen (Fletcher, 2014: 8).

Trabajar para reducir los impactos resultantes de la elaboración de fibras y tejidos es un buen punto de partida para comenzar a tomar distancia de los procesos tradicionales del diseño de moda e indumentaria, pero no logra cobrar la fuerza suficiente para poder generar los cambios de paradigma necesarios para transicionar hacia los futuros deseados de sostenibilidad. Alternativamente, si se parte de la categorización del diseño de la moda e indumentaria como práctica social más allá de lo meramente material, se podrá ahondar más profundamente en el potencial de la vestimenta de satisfacer varias de las necesidades humanas listadas por Max-Neef (1991) en su trabajo sobre las escalas del desarrollo humano o Human Scale Development, desde la subsistencia, a la participación y la construcción de la identidad. Esta consideración resulta necesaria para comprender el funcionamiento de la moda como un sistema conformado por múltiples partes y actores que cumplen una miríada de roles.

A partir de esta perspectiva, se podrá analizar la situación actual de las prácticas, para detectar las problemáticas asociadas y comprender mejor los impactos que tienen los procesos productivos y de consumo de la industria en el ambiente y en los individuos que conforman a la sociedad, ya que: 
(...) el análisis del Diseño, entendido desde la perspectiva de la problematización, comprende o supone establecer a través de un proceso organizado, un cuestionamiento reflexivo y crítico de la situación real del problema de diseño en su contexto, frente a la situación deseable o posible que resulta de una especulación o acción prospectiva (Di Bella, 2020: 98).

Poder profundizar en este análisis situacional del Diseño de Moda e Indumentaria, servirá para contextualizar las áreas de problema de la industria, sus consecuencias y sus causas principales, para luego proponer una posible intervención dentro del sistema desde distintos puntos de apalancamiento (Meadows, 1997), utilizando el enfoque o la lente del Diseño para la Transición (Irwin, Kossoff y Tonkinwise, 2015) con la finalidad de evolucionar hacia una industria de la moda e indumentaria enfocada en nuevos modelos de negocios con perspectiva de sostenibilidad ética y ambiental.

El futuro de la industria de la indumentaria y los textiles dependerá de nuestra capacidad de reducir su carga ambiental y social a través de la totalidad de su ciclo de vida al establecer una base de buenas prácticas que nos permitan implementar múltiples estrategias para afrontar los problemas vinculados a la sostenibilidad (Fletcher, 2014: 43).

En este escenario, el diseñador se posiciona como agente de cambio y utilizará las distintas herramientas del Diseño para la Transición sabiendo que "se necesita un enfoque más holístico para distinguir entre las consecuencias y las causas de raíz de un problema perverso, que a menudo involucran a las dinámicas sociales que las conforman" (Irwin, 2017:150). Esta intervención se elaborará sobre la base de las metodologías del Upcycling que facilitarían la transición hacia sistemas de economía circular, que trabajen para fomentar el bienestar de los individuos y del medioambiente ${ }^{1}$.

En los circuitos de economía lineal, basados en la búsqueda de un crecimiento económico sostenido, se establecen formas de promover constantemente el consumo, respondiendo al modelo reduccionista que caracteriza el funcionamiento de los sistemas de control de la sociedad hipercapitalista: "Los flujos de energía y materiales requeridos para sostener el crecimiento industrial están agotando los recursos no renovables y deteriorando las capacidades de los recursos renovables" (Meadows et al, 2006: 129). Esto se vincula con la creación y el establecimiento de la obsolescencia programada o planificada, para acortar la vida útil de los productos con el fin de incentivar la continuación de la producción y el consumo de manera prácticamente infinita. En el caso particular de la industria de la moda e indumentaria, la obsolescencia muchas veces se promueve atada a factores psicológicos, como la necesidad de renovación constante de la imagen, ligada a la capacidad de comunicar la identidad a través de la vestimenta. Cline postula que "como la moda se expresa públicamente, todos pueden ver quién no se encuentra alineado; $y$ por eso, para mantenerse al día con los estilos más recientes, tienen que comprar de manera constante" (2014, p. 11). Concretamente, 
(...) se ha podido comprobar que el consumidor, cuando adquiere un bien, no lo hace solamente por sus cualidades de eficiencia o funcionalidad, sino además por su significación, por lo que simboliza y por la serie de valoraciones emotivas que la posesión de ese bien expresa (Veneziani, 2012:74).

Tal como se mencionó anteriormente, las identidades de los individuos en la actualidad, se despliegan siempre cambiantes, fluyendo dentro del marco de las sociedades líquidas participando de la sociedad del consumo, por lo que la moda e indumentaria se ha convertido en un lenguaje que facilita la comunicación de estas identidades fluidas, y a su vez cataliza el ciclo de consumo constante: si la identidad cambia, la imagen debe acompañar y representar esa transformación y para ello, es necesario consumir. Aquí, la indumentaria se remite a ser interpretada como valor signo, donde

(...) se puede afirmar que los sistemas de signos visuales implican un alto grado de abstracción y un código común para su interpretación y reconocimiento; es por este motivo que refuerzan determinadas estructuras de pensamiento arraigadas en el inconsciente colectivo, que son símbolo y se reconocen e interpretan mediante el consenso social (D’Ortenzio, 2020:127).

Si esta relación entre consumo e identidad no se regula de alguna manera, desencadena en lo postulado por Max-Neef (1991), quien considera que el consumo se vuelve dañino y genera impactos irreversibles en los recursos del planeta cuando se hace a gran escala y en proporciones desmedidas, sin embargo es importante considerar que:

(...) el consumo - una búsqueda de satisfacción- no es inherentemente negativo, ni todos los deseos de consumo son creados artificialmente. Los bienes materiales como la vestimenta son rutas importantes hacia el bienestar; pueden empoderar a sus usuarios a alcanzar necesidades fundamentales (Fletcher 2014:143).

En consecuencia, el propósito de este trabajo, no es fustigar al consumo de moda e indumentaria, sino de proponer alternativas a los circuitos de producción y consumo tradicionales a través de un cambio de modelo de negocios que buscará modificar las conductas de los consumidores vinculadas a sus estilos de vida. Se busca frenar o desacelerar el proceso de obsolescencia programada de la moda e indumentaria a través de la incorporación de metodologías del Upcycling como estrategia de economía circular que impulsaría las modificaciones necesarias para transicionar hacia un futuro de la industria con tendencia a la sostenibilidad ética y ambiental. El Upcycling, basado en la reparación y la reutilización de prendas en desuso, tiene como principales ejes la personalización o customización de la indumentaria a partir de lo que ocasionalmente se categoriza como técnicas heredadas, tales como el emparchado de estilo patchwork, el teñido, la pintura textil y el bordado.

También se desenvuelve la práctica de la deconstrucción dentro del Upcycling, donde las prendas son desarmadas parcial o totalmente para crear nuevas prendas utilizando las 
partes de manera más experimental (p.ej. convertir las mangas de una camisa en la parte delantera de una falda).

El Upcycling es distinto al reciclado, ya que tiene como finalidad la reutilización diseñada creativamente de la indumentaria descartada de modo tal que resulte en un producto o una prenda de mayor calidad y mayor valor percibido del que originalmente tenía. Por otro lado, el reciclado de la indumentaria, se trata de descomponer las prendas desechadas para utilizar el material obtenido para recomponerlo en fibras que serán convertidas nuevamente en prendas del mismo tipo que fueron inicialmente desechadas.

Reparar y re-acondicionar textiles y prendas ha cobrado impulso por un renovado interés en las habilidades artesanales (sea por factores éticos o por elecciones de estilos de vida) reclamados como practicas creativas importantes que reconocen el valor de la cultura material en la organización de la vida de los individuos. Muchas de estas habilidades se han convertido en las herramientas clave de un grupo pequeño pero significativo de diseñadores y productores, que usan una variedad de técnicas como la reorganización, el embellecimiento, y la sobre-impresión para darle una nueva vida y un valor agregado a prendas descartadas, manchadas, y rotas, y para evitar o demorar su llegada a los vertederos. Las prendas remodeladas y re-elaboradas tienen a ser únicas y terminadas a mano y por ello son fácilmente asociadas a los valores de sostenibilidad (Fletcher, 2014:120).

Debido a la capacidad del Upcycling de extender el ciclo de vida de las prendas, generando valor agregado a través de la personalización como forma de representar mejor la identidad de un individuo, se pueden desacelerar los procesos de producción y consumo tradicionales dentro de la industria, tomando distancia de la homogeneidad globalizada del fast fashion. Aquí se considera que aquí existe un vínculo estrecho con la idea de la indumentaria basada en los valores, como representación tangible del capital cultural de una región, de su historia, sus normas, sus creencias y como herramienta de comunicación visual en la construcción de la identidad, tanto de los individuos como de un colectivo, al respecto argumenta Fletcher:

Las necesidades emocionales satisfechas por la indumentaria dentro de contextos individuales y sociales, son complejas, sutiles e inagotables. Desafían muchos argumentos ambientalistas y su cruda categorización de la moda únicamente como una serie de prácticas que causan el detrimento del medioambiente y del bienestar de la humanidad. No se podrá transformar el potencial de sostenibilidad de la moda hasta que no se comience a comprender su significancia como satisfactor de necesidades humanas inmateriales y psicológicas (Fletcher, 2014:145).

Si bien la moda e indumentaria y sus prácticas de diseño pueden satisfacer necesidades fundamentales como la participación, la identidad y la creación, los resultados de sus procesos de producción y consumo resultan paradojales, ya que también dan lugar a lo que 
Max-Neef (1991) denomina como pobreza, o la inhabilidad de satisfacer necesidades básicas, al emplear mano de obra en condiciones insalubres y al contribuir al agotamiento de los recursos naturales, entre otras problemáticas, y al mismo tiempo se vincula con lo expresado por Irwin acerca de los impactos dentro del sistema de un problema perverso, cuando se implementan

(...) pseudo-soluciones, que se enfocan en mejorar síntomas en lugar de causas raíces, por lo que podrían involuntariamente causar o exacerbar problemas en otra área del sistema. Si no se identifican correctamente, estas pseudo-soluciones pueden a su vez convertirse en problema perverso (2017, p.150).

Actualmente en el diseño de moda e indumentaria, comúnmente se desenvuelven estas pseudo-soluciones ya que se encuentran atadas al modelo de economía lineal ya mencionado, implicado en fortalecer una estructura de poder comandada por las marcas -o conglomerados de marcas- dominantes de la industria:

(...) Las ideas dominantes sobre economía, negocios, estructuras organizacionales y preferencias culturales, junto con el modo en que los individuos usan vestimenta, son los factores determinantes que dictan el paradigma vigente de la moda (Fletcher, 2014:143).

Aquí queda en evidencia que para impulsar cambios en la industria de la moda e indumentaria, se requiere de la participación colaborativa de múltiples actores o Stakeholders, y para poder entender mejor de qué manera sus acciones impactan e intervienen dentro del sistema, se analizará a continuación el circuito funcional de producción y consumo de una temporada y colección promedio de una marca líder en ventas -principalmente en línea- en el mercado internacional de moda e indumentaria.

Se tomó la decisión de analizar el funcionamiento de una marca líder de ventas online de indumentaria tipo streetwear con una mayoría de ventas en línea para poder asociarlo más fácilmente al grupo de consumidores o usuarios sobre el cuál se trabajará en este análisis. Esta relación se establece ya que:

Las marcas o las compañías rara vez se dirigen a un público universal. Cada vez más, las marcas definen a su público objetivo atendiendo a variables actitudinales o de estilo de vida, trascendiendo las clásicas segmentaciones por sexo, edad y clase social (Gil Mártil, 2009:34).

El grupo de consumidores elegido para situar el foco de este estudio de caso será el de personas de sexo femenino de entre 16 a 35 años, centralizada en los países del norte de América pero cuyos estilos de vida se repiten y reflejan en distintos países en Latinoamérica, Europa y Asia, ya que

(...) todos los medios de la cultura de masas sirven para fortalecer las coacciones sociales que pesan sobre la individualidad, al excluir toda posibilidad 
de que el individuo se mantenga de algún modo en pie frente a la maquinaria atomizadora de la sociedad moderna (Horkheimer, citado en Croci y Vitale, 2012:104).

Estos grupos de personas serán, de aquí en adelante, denominados los influencers, por su altísima presencia en redes sociales y su capacidad de influenciar sobre las actividades de consumo de sus pares, gracias a la democratización de las tendencias de lujo que se vuelven accesibles al público general, por la poderosa presencia de estas mismas marcas de fast fashion en la venta online. Se menciona que este análisis, no tiene como objetivo realizar una crítica sobre los mecanismos de una determinada marca y/o grupo de marcas, sino que utiliza la información recolectada sobre esta de manera puntual, para generar contexto y así extensivamente, poder dar cuenta del estado actual de la industria, las relaciones que se establecen entre quienes la conforman y los impactos que se desprenden de ella, ya que el eje central del desarrollo de este trabajo, se orienta hacia la implementación de soluciones que posibiliten la generación de nuevos modelos de negocios sostenibles, teniendo en cuenta que la escala de los problemas del Diseño está cambiando, y esto exige una mayor especialización en los casos más específicos, mientras que en los más amplios, está adquiriendo much a mayor escala y compromiso a nivel de los sistemas en los que se requiere la colaboración de múltiples actores y disciplinas (Scupelli, 2018: 111-112 en Di Bella, 2020: 96).

Para poder detallar mejor la relación entre la marca y la categoría de consumidores analizados, se resalta que actualmente, esta cuenta con 19.3 millones de seguidores en Instagram en su cuenta principal que apunta a la venta de indumentaria para mujeres de talles regulares y del rango etario mencionado anteriormente. En sus otras cuentas de Instagram -una que vende indumentaria femenina de talles grandes o plus size y otra que comercializa indumentaria masculina- hay un total de 3.8 millones y 2.5 millones de seguidores respectivamente. Esto equivale a un total de 25.6 millones de seguidores repartidos entre sus distintos canales de la plataforma. Aquí se destaca la elevada popularidad de la cuenta que comercializa prendas de talles regulares por encima de aquella que comercializa prendas plus size; tendencia que se repite innumerables veces en los circuitos de la moda rápida donde los cuerpos de los individuos se encuentran altamente regulados por la presión social y mediatizados por la cultura a la que pertenecen (Barreiro, 2004):

El orden visual intervino en la manera en que el sujeto de la modernidad ha conocido y representado su propio cuerpo. Determina los modos de tipificar los cuerpos de las personas y de interpretar lo social y a través de la dimensión corporal se ejerce la regulación y el control social de los sujetos. La sociología ha interpretado las prácticas del vestir y en especial a la moda, como hechos sociales que ponen en evidencia la construcción cultural de la conformación social de los cuerpos (Zambrini, citado en Figari, Jones y Pecheny, 2008:142).

Según la información recolectada de una entrevista de Women's Wear Daily llevada a cabo en 2018 con el CEO de la marca, se estima que ésta lanza entre 600 y 900 estilos nuevos cada semana, con un $80 \%$ de las prendas que se elaboran de manera local con procesos productivos que demoran como máximo 2 semanas (Hughes, 2018). Una vez que el stock 
de las prendas se agota, durante un período de aproximadamente 15 días, comienza el ciclo nuevamente. Cabe destacar, además, que desde el diseño y la creación del concepto de una prenda a la elaboración de una muestra lista para fotografiar y publicar en redes sociales, hay un período de tan solo 24 horas. Reflejando esta aceleración de los tiempos de producción, el CEO de esta compañía afirmó que se ha "transformado la moda rápida en moda ultra-rápida” (Hughes, 2018). Si bien la marca tiene tiendas físicas en distintos puntos de California, su dueño ha declarado que prefiere alcanzar la mayor cantidad de consumidores posibles, distribuidos en la mayor cantidad de países y para lograrlo, se focaliza el volumen de sus actividades en las redes sociales, publicando contenido aproximadamente cada 30 minutos a través de sus cuentas de Instagram. Debe mencionarse que también hace envíos a nivel global, y que los envíos nacionales (dentro de Estados Unidos) sólo se demoran un promedio máximo de 48 horas. Para las ventas tanto nacionales como internacionales de las prendas y los accesorios comprados en línea, no hay devolución del dinero en caso de que los consumidores no estén satisfechos con el producto, sino que únicamente se ofrecen créditos para futuras compras. Además, el costo de envío para devolver una prenda o para pedir el cambio o reemplazo, termina resultando más elevado que el precio por el que se pagó al inicio. Esto lleva a que los productos de esta marca tengan una altísima taza de descarte y reemplazo, y muy poca permanencia en los guardarropas de las personas.

El mercado de la moda de hoy es altamente competitivo, y la necesidad constante de actualizar los rangos de productos significa que hay movimientos inevitables por parte de los vendedores de extender el número de temporadas, afectando la frecuencia con la que toda su mercadería es cambiada (Bhardwaj y Fairhurst, 2010: 166).

Por otro lado, vinculado al incentivo del consumo, cabe mencionar que tan solo una publicación en colaboración con una celebridad o figura de la cultura popular con altísimo alcance en redes sociales como, p.ej. la cantante Cardi B con 78.1 millones de seguidores (según lo reflejado por Instagram, en Octubre de 2020) pueda atraer ventas de hasta $\$ 50.000$ dólares (Hughes, 2018). Esto se vincula al poder de amplificación de las redes, pudiendo hacer crecer una marca o empresa a escala global en períodos de tiempo hiperacelerados y sin la necesidad de realizar grandes inversiones en estrategias de mercadotecnia tradicionales. En el caso puntual de esta marca de fast fashion, considera que todos sus clientes son influencers, ya que se los incentiva a publicar fotos en las redes una vez que reciben sus prendas, e incorporando hashtags acordes a la identidad e imagen de la marca, con la posibilidad de que sus fotos sean compartidas en el perfil oficial de la marca, asunto que se sostiene en que

Cuando hablamos del papel desempeñado por la moda y el vestir, es importante reconocer que las identidades tienen un sentido social. El individuo puede querer destacar, pero también quieren encajar dentro de un grupo (Entwistle, 2000:160) y 
(...) cuando ajustamos nuestro comportamiento al grupo, además de ganar en eficiencia con menor riesgo de equivocarnos, también los hacemos en confianza, salvaguardando nuestra autoestima (Gil Mártil, 2009:50).

Esta actitud de retroalimentación entre la marca y su público, y a su vez entre el público y sus pares, acrecienta el tiempo que los individuos pasan en las redes sociales, dando lugar a lo que se conoce como la cultura del influencer, que se ubica dentro de la cultura de la inmediatez que caracteriza a la industria del fast fashion, donde "el vestido es una expresión indirecta de cada individuo, y no sólo está incluido en forma definitiva en nuestra propia imagen, sino que es parte de la imagen del otro" (Pampliega de Quiroga y Pichon-Riviere, 1985:40).

Si bien no se encuentran datos concretos sobre el manejo de los desechos y sus impactos en el ambiente de este caso analizado, se pueden mencionar algunas cifras representativas de la industria del fast fashion en general, y en primer lugar, se menciona que durante el 2019 menos del 11\% de las marcas dominantes implementó estrategias de reciclado en sus circuitos productivos (Baptist World Aid Australia). Según información de la Fundación Ellen MacArthur, se calcula que por la falta de sistemas de reciclaje y reutilización de desechos textiles y de prendas usadas se pierden de manera anual, más de $\$ 500$ billones de dólares. Esto se debe en parte a las prendas que los usuarios desechan, pero también a aquellas que las mismas marcas no logran vender (excedente de stock), que usualmente van a parar a basurales a cielo abierto o se incineran. En 2019 esto se vio reflejado de manera concreta, en la consideración de que 3 de cada 5 prendas de fast fashion acaban en vertederos (Clean Clothes Campaign, 2019). Otro dato a considerar, es que la mayoría de las marcas dominantes del fast fashion, incluyendo la que se analiza, alcanzan un puntaje menor al 10\% en el índice de transparencia de la moda (Fashion Transparency Index, 2020), situación que se asocia también al impacto de las prácticas productivas del fast fashion en el bienestar de sus empleados y también de los usuarios:

Producir indumentaria y textiles involucra una de las cadenas más largas y complejas en la industria de la manufactura, tomándose de energía, agua, mano de obra, y otros recursos, convirtiéndose en un sector de alto impacto. Se vincula con abusos laborales tales como los indices de pobreza, horas de trabajo excesivas, horas extras obligatorias, falta de seguridad laboral y negación de los derechos sindicales (Fletcher, 2014:51).

La Guía de Moda Ética (Ethical Fashion Guide), anunció que durante el 2019 el 68\% de las marcas no adhirieron a normativas de igualdad de género, incluso considerando que el $80 \%$ de los empleados del sector textil y de indumentaria son mujeres. El muestreo llevado a cabo por Fashion Checker durante el tiempo transcurrido del año 2020 demostró que los salarios que ofrecen el 93\% de las marcas de fast fashion no alcanzaron el monto mínimo. En el caso particular de la marca analizada, se observó que a las costureras que trabajan en los talleres de Los Ángeles, se les llegó a pagar tan sólo \$2.77 dólares por hora y que desde el año 2016, la marca debe $\$ 3.8$ millones de dólares en salarios, afectando a cientos de trabajadores. En la ciudad de Los Ángeles hay una gran cantidad de fábricas textiles que son 
contratadas para producir prendas para distintas marcas de moda rápida, donde los trabajadores cobran de manera informal, con salarios extremadamente bajos ya que se trata de personas que comúnmente no denunciarían estas condiciones por estar indocumentadas. Esto sucede ya que las fábricas están en competencia constante con las ofertas de mano de obra en países periféricos donde se paga incluso menos a los empleados (Kitroeff, 2019).

Los impactos ambientales y sociales de producir [prendas] textiles son muchos y variados, y exponen la interconectividad de los flujos de recursos que apuntalan hasta las decisiones de diseño más simples, significando que debemos reconocer esta complejidad en nuestra labor [...] para cambiar el foco desde la cantidad a la calidad. Debemos preguntarnos qué es lo más apropiado para nuestro producto y qué ayudará más a las personas. Debemos diseñar con una visión más plural, descentralizada y diversa acerca de lo que la industria puede ser (Fletcher, 2014:44).

\section{Ciclo de vida del proceso de producción y consumo}

A partir del despliegue de los datos anteriormente mencionados, se puede realizar una construcción del ciclo de vida del proceso de producción y consumo que se desprende de su esquema funcional de mercado. Se resalta que dicho ciclo de vida se encuentra delineado por la obsolescencia programada que comúnmente se asocia con la moda rápida y que "muestra muy poco interés por el medioambiente y los derechos humanos. Reconstruyó toda la industria textil y del vestido a su imagen y semejanza: cambió de manera muy profunda la idea que tenemos del vestir" (Cline, 2014:12); y que "la extensión de tiempo durante la que se utiliza una prenda es influenciada por la cultura, el comportamiento, la psicología, el conocimiento y las habilidades, así como también los factores puramente materiales" (Fletcher, 2014:194). En este ciclo de obsolescencia programada (Ver Figura 1), se parte del diseño de las prendas y la elaboración de las muestras, que luego son llevadas a cabo en los sectores de producción locales e internacionales mientras que se publicitan a través de redes sociales con la implementación de colaboraciones mediáticas. 


\section{PROCESO DE LA OBSOLESCENCIA PROGRAMADA}

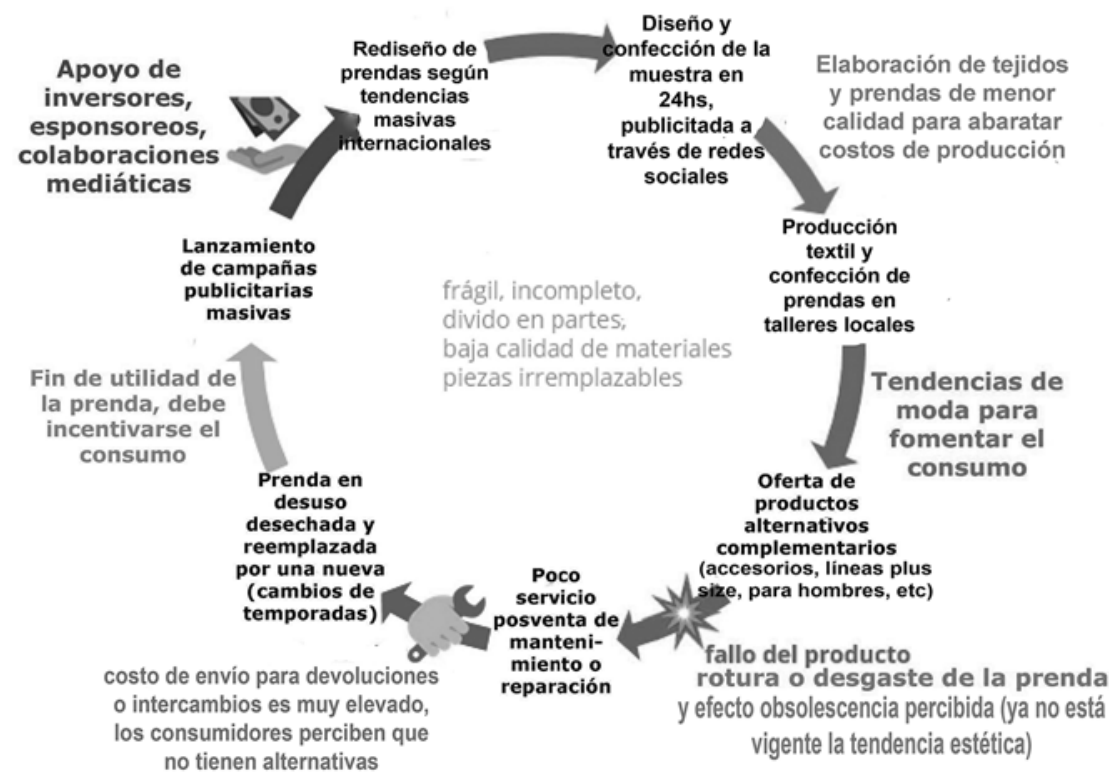

Figura 1. Esquema de Obsolescencia Programada basado en el caso analizado (Fuente: Alexandra Vinlove).

Una vez producidas las prendas, están listas para ser distribuidas a los puntos de venta físicos y a los consumidores que piden online a través de sistemas de envíos express, quiénes reciben sus prendas y son incentivados a publicar fotos en Instagram utilizando ciertos hashtags para diseminar el contenido entre un público mayor y así fomentar más ventas y sistemas de canje con la marca. La acelerada elaboración de las prendas se desenvuelve principalmente gracias a recortes en la calidad de los textiles y los procesos productivos, lo que implica que se desgastarán a mayor velocidad y/o que los calces sean elaborados a partir de patrones universales que no se ajustan a una gran variedad de cuerpos. A esto se suma que los costos de intercambio o devolución de las prendas con roturas o que no le entren a los consumidores son tan elevados que prácticamente se imposibilita el desempeño de los servicios pos-venta de reparación o mantenimiento. La consecuencia de esto es que las prendas se descartan rápidamente ya que los consumidores consideran que se llegó al fin de la vida útil de la prenda, y que no tienen otra alternativa que reemplazar sus prendas en desuso por productos nuevos, reiniciando e incentivando el circuito de consumo. 


\section{Mapeo de conexión del problema perverso (Wicked Problem)}

A partir de este análisis del ciclo de producción y consumo de la marca seleccionada, se realiza el mapeo de conexión con el Wicked Problem (Rittel y Webber, 1973), que se encuentra en constante evolución:

Estos problemas son considerados como una discrepancia entre el orden natural de un objeto, espacio o situación, es decir entre cómo está actualmente y como debería de estar. Para acercarse a las posibles soluciones de estos conflictos que se presentan como un entramado, resulta imprescindible incorporar la ética a través de una profunda preocupación por la sociedad y por el medioambiente. Aquí se plantea una relación de triada en el diseño, las personas y el medioambiente, considerando lo que las personas hacen a nivel social y ecológico (Vinlove, 2020:155).

Los impactos resultantes de este problema perverso (Ver Figura 2) se categorizan de 5 maneras, según su área de desarrollo, siendo estas: Infraestructura y tecnología, política y gobierno, economía y finanzas, ambiente y ecosistema y, por último, las relaciones sociales donde participan los Stakeholders o actores intervinientes. Las principales consecuencias del circuito de producción y consumo tradicional dentro de la moda rápida se reflejan en la infraestructura y tecnología a través de la baja calidad y corta durabilidad de los textiles y las prendas, causadas por recortes en la línea de producción y por el estado de precariedad de los talleres que, además, no cuentan con maquinaria actualizada que permita generar textiles y prendas de mayor calidad con menor utilización de recursos, razón por la que "En este circuito las prendas son desechadas rápidamente, ya que tienen poco valor percibido: la calidad textil es pobre y la confección no aguanta los procesos de lavado, promoviendo su reemplazo rápidamente" (Fletcher, 2014:191). 


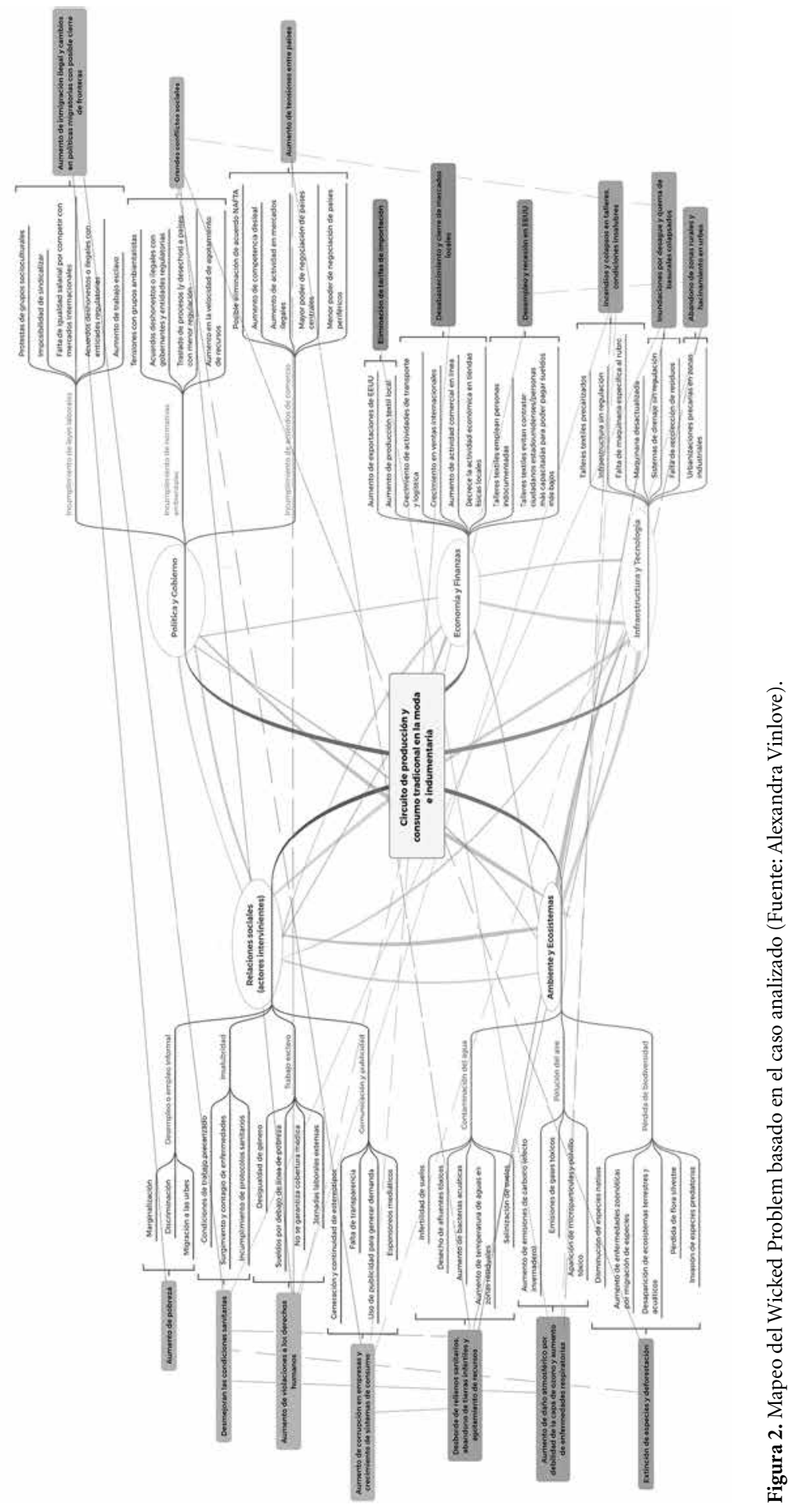


En cuanto a la política y gobierno, la principal consecuencia observada es el incumplimiento de leyes laborales y ambientales, causado por la falta de regulación en los procesos que se desarrollan dentro de las fábricas textiles y por las decisiones de diseño y producción de la marca analizada.

Dentro de la categoría de economía y finanzas, se detecta como principal consecuencia la dificultad de generar mercados alternativos de moda lenta o con perspectiva de economía circular, causada por la postura dominante de las grandes marcas de moda rápida (incluyendo la que se toma como punto de análisis en esta investigación), que buscan asegurar la continuación del estado actual de la industria, es decir que "la fórmula de la moda sofoca la creación de alternativas, empujando los precios hacia abajo, imposibilitando la participación de los pequeños productores como competencia en el mercado" (Fletcher, 2014:222).

Las principales consecuencias en la categoría de ambiente y ecosistemas se observan en el agotamiento de los recursos no renovables, en la contaminación del agua y en la polución del aire, causadas por la alta carga energética de la producción y distribución de las prendas de moda rápida, sumada a la falta de tratamiento de los desechos que generan las prendas una vez que se da por terminada su vida útil.

Por último, dentro de la categoría de relaciones sociales, se detectan como consecuencias las condiciones de trabajo insalubres, la insuficiencia salarial de los trabajadores textiles, la discriminación, la desigualdad de género y el fomento de estereotipos de belleza limitantes. Estas consecuencias se deben a los intereses de los actores que dominan la industria que se focalizan en la generación de ganancias y crecimiento económico sin tener en cuenta los impactos resultantes en la vida de los individuos.

Todas las consecuencias de este problema perverso y sus causas de raíz se vinculan entre sí, y se debe tener en cuenta que realizar un cambio en una de las 5 áreas o categorías de impacto, tendrá repercusiones en las otras 4 y es por ello que debe trabajarse de manera colaborativa con los Stakeholders influyentes en cada categoría, para diseñar intervenciones más allá de una solución concreta, apuntando a generar transformaciones a nivel sistémico. Lockton y Candy postulan que las "visiones compartidas de temas como el cambio climático, salud, inmigración, identidad, leyes, mitos y creencias podrán motivar colaboraciones" (2017: 30), sin embargo, debe tenerse en cuenta que:

(...) la resolución de problemas perversos requiere de una miríada de intervenciones en múltiples niveles dentro de contextos espacio-temporales extremadamente amplios. Los problemas perversos existen a múltiples niveles de escala y siempre tienen sus raíces en el pasado porque lleva años, décadas o incluso más para que un problema se vuelva perverso (Irwin, 2017: 163).

Una vez realizado el mapeo de Wicked Problem se detallan a continuación lo que se consideran los principales aspectos insostenibles y los principales aspectos sostenibles del análisis realizado. Los aspectos insostenibles en cuanto al impacto ambiental, son el uso excesivo de energía y recursos en los procesos de producción y distribución de las prendas, y la falta de manejo de residuos textiles generados por las prendas descartadas. En lo referente al impacto social, se destacan las condiciones de trabajo insalubres en los talleres textiles y los salarios insuficientes que reciben las costureras empleadas y, por otro lado, el fomento 
de estereotipos de belleza limitantes debido a la falta de representación diversificada en los medios de comunicación, incluyendo las redes sociales. Otro aspecto insostenible de impacto social, es la falta de información por parte de los consumidores acerca de cómo se elaboran las prendas que adquieren y los impactos de sus decisiones de consumo sobre el ambiente y los individuos.

Como principales aspectos sostenibles, se advierte que la marca analizada tiende mayoritariamente a producir sus prendas localmente, posiblemente disminuyendo el uso de recursos y emisiones al acortar distancias y trabajar de manera centralizada (aunque este aspecto solo tiende a la sostenibilidad ya que continúa impactando con fuerza). Desde la perspectiva del impacto social, el aspecto sostenible se observa en la posibilidad de los consumidores de satisfacer la necesidad de representar su identidad a través de la indumentaria, así como también la generación de vínculos a través de redes sociales con grupos que compartan intereses y estilos de vida similares.

\section{Esquema de los actores intervinientes (Stakeholders)}

A partir de este análisis del problema perverso y sus impactos, se analizan los actores intervinientes dentro de este sistema. Así, se selecciona como principales Stakeholders (Ver Figura 3) del caso a su grupo de consumidores (influencers, mujeres de talla regular de entre 16 a 35 años de edad), a los empleados de los talleres textiles contratados para realizar las prendas, a los dueños de dichos talleres y al Departamento de Labor de Estados Unidos. La participación activa de todos los actores intervinientes resulta crucial, ya que "el Diseño para la Transición favorece un enfoque basado en el consenso de los múltiples Stakeholders para ayudar a trascender oposiciones, conflictos y las limitaciones de mapas cognitivos antiguos para igualar las relaciones de poder" (Irwin, 2017: 158).

Se observa que las relaciones entre los Stakeholders pueden ser de tres tipos: mixtas, conflictivas, y simbióticas, desde donde se podría establecer que la relación entre la marca analizada y su grupo de consumidores es simbiótica ya que las acciones de cada uno se complementan entre sí (oferta-demanda, producción-consumo). Se menciona que no se detalla la relación de los consumidores con los demás actores intervinientes restantes, ya que se considera que ahonda en aspectos socio-culturales que precisarían de una investigación profunda sobre ética que no se encuentra dentro del área de estudio de la autora. 


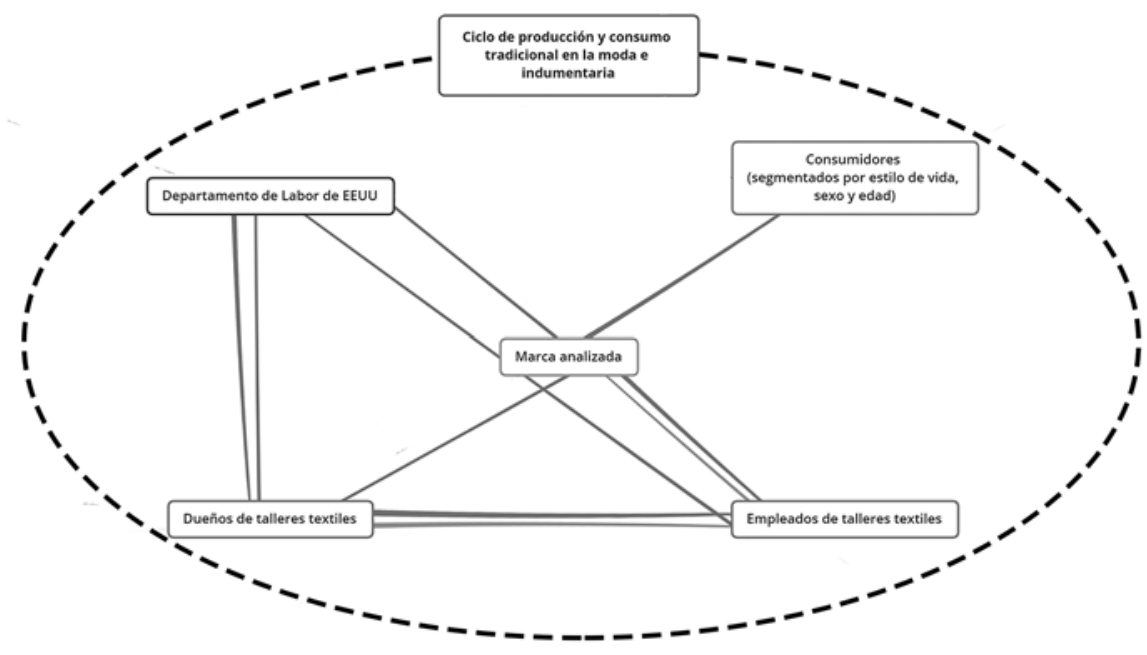

Figura 3. Esquema de los Stakeholders basado en el caso analizado (Fuente: Alexandra Vinlove).

La relación entre los dueños de las fábricas textiles y sus empleados podría considerarse mixta, ya que las fabricas necesitan de mano de obra para poder funcionar y los trabajadores necesitan de un salario para vivir (simbiosis) pero existe un gran desequilibrio entre este vínculo, debido a la condición de indocumentado de muchos de los trabajadores que se ven obligados a participar de empleos en condiciones precarias por no tener acceso a otros puestos y los dueños de las fábricas sacan provecho de esta situación (conflicto). Por otro lado, la relación entre los dueños de las fábricas textiles y la marca analizada es simbiótica ya que ambas partes resultan favorecidas al generar ganancias en el intercambio de servicios. La relación entre el Departamento de Labor de Estados Unidos y los empleados de las fábricas textiles también se considera mixta, ya que si bien esta institución debería funcionar como ente regulador de las actividades laborales para asegurar que los trabajadores reciban salarios dignos y realicen sus actividades en condiciones sanitarias, no necesariamente se da siempre de esta manera. Así se establecen relaciones entre todos los Stakeholders involucrados, que se sitúan dentro del sistema del problema perverso en forma de red, donde todas las partes están interconectadas entre sí.

(...) De esta manera se observa la naturaleza compleja de las relaciones entre los Stakeholders, por esto resulta necesario considerar y analizar todos los puntos de vista y posibles relaciones para poder intervenir en el sistema con la mayor eficacia posible. No sería efectivo que los diseñadores intenten imponer un orden fijo ni crear una única solución inmediata, sino que deben poder 
detectar los pequeños indicios de cambio, amplificarlos y posicionarse como catalizadores de esa transformación para el logro de un nuevo orden,concepto que se vincula directamente con el Diseño para la transición (Irwin, Kossoff y Tonkinwise, 2015).

\section{Backcasting, Futuro deseado, Satisfactores e Intervenciones en el Sistema}

Habiendo realizado el mapeo de problema perverso y el estudio de las relaciones establecidas entre los actores intervinientes, se utiliza una de las metodologías del Diseño para la Transición, conocida como backcasting, mencionada por Lockton y Candy (2017) para plantear cuál sería uno de los futuros deseados para la industria, imaginado de manera idealizada para luego trabajar en retroceso, hasta llegar a la elaboración de una propuesta de intervención que pueda ser implementada en tiempo presente. Deben realizarse análisis críticos y cuestionamientos profundos para poder comenzar a visualizar cuál sería uno de estos futuros deseados, a quienes beneficiaría, cuáles serían sus impactos, y demás.

Esta otra forma de ver, se trata de la creación de escenarios hacia atrás desde un punto postulado en el futuro. Si estipulamos que el futuro que nos interesa se ve así, ¿Qué haría falta para que eso suceda? ¿Qué tendría que ocurrir? (Lockton y Candy, 2017: 32).

Para esto, el proceso se divide en tres estados: el presente (estado actual), el futuro (estado deseado o esperado), y la fase intermedia (la transición de un estado a otro) (Lockton y Candy, 2017). Bajo esta estructura, se sitúa al problema perverso en el estado presente, y en el estado futuro se ubicaría al desarrollo de la industria de la moda e indumentaria con sostenibilidad ética y ambiental, basada en un modelo de economía circular (incluyendo la utilización de las metodologías del Upcycling), y que cumpla con los objetivos de desarrollo sostenible ONU de trabajo decente, producción y consumo responsables, acción por el clima y ecosistemas, salud y bienestar, y reducción de las desigualdades a través de alianzas (Ver Figura 4). 


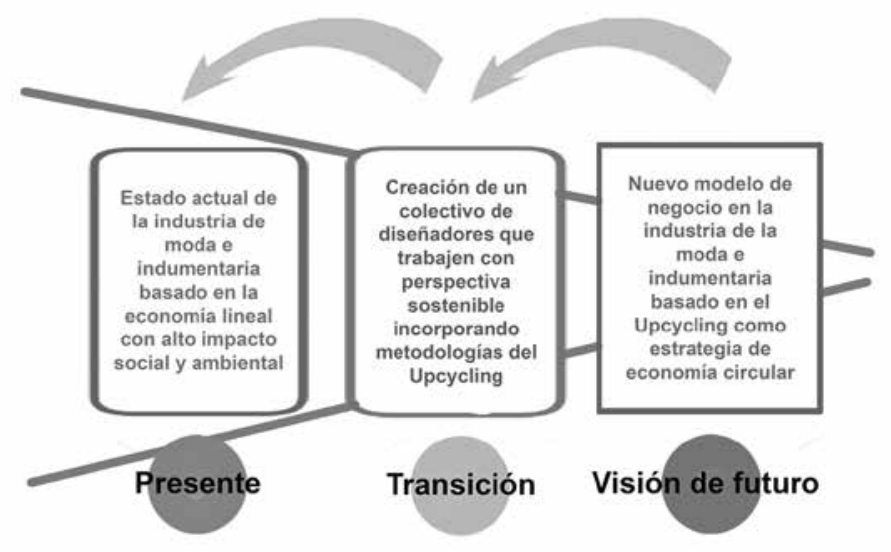

Figura 4. Esquema de un posible Backcasting basado en el caso analizado (Fuente: Alexandra Vinlove).

Para comenzar a transicionar desde el presente hacia el futuro esperado, se debe realizar una intervención estratégica dentro del sistema donde actualmente se desenvuelven las problemáticas que imposibilitan alcanzar ese futuro deseado. Aquí se entiende por transición a "las transformaciones con explicita direccionalidad hacia la sostenibilidad a nivel societario [...] haciendo énfasis en orientaciones sistémicas a largo plazo" (Gaziulosoy, 2017: 72). La utilización de la metodología del backcasting, comprende que diseñar para un futuro que todavía no existe puede ser complejo y por eso hace referencia al futuro deseado o esperado, que utilizado "como lente, es una invitación: ¿de qué manera tomarías una idea -cualquier idea-del futuro para darle vida concretamente, en el ahora?" (Lockton y Candy, 2017:39).

Para poder realizarlo, se diseña una propuesta que trabajará sobre los 12 principios de apalancamiento o Leverage Points que postula Meadows (1997), y surge de la consideración de la moda e indumentaria como posible satisfactor de algunas de las necesidades que enuncia Max-Neef (1991):

- En primer lugar, podría satisfacer la necesidad de la creación, a través del diseño.

- Luego, podría satisfacer la necesidad de subsistencia a través de la generación de empleos y la capacidad de abrigo, teniendo en cuenta las cualidades físicas y materiales de las prendas.

- También podría satisfacer la necesidad de participación a través de las relaciones sociales que se desarrollan entre grupos de intereses compartidos, vinculado a lo que se mencionó anteriormente sobre la indumentaria como valor signo.

- Por último, se estima que podría satisfacer la necesidad de identidad, al servir como herramienta de comunicación visual o no verbal de la identidad de género, la identidad cultural basada en las creencias y costumbres de una región o la identidad de cada individuo, representando sus gustos, preferencias e intereses. 
Las necesidades mencionadas arriba, son aquellas que Max-Neef postula como esenciales para el desarrollo de la vida humana y las clasifica como finitas y universales (iguales para todos los individuos en todas partes del mundo).

Establecer la satisfacción de necesidades como criterio en la reconcepción de los estilos de vida es una estrategia importante para desafiar los paradigmas socio-económicos y políticos dominantes dentro de los cuales han evolucionado la mayoría de los problemas perversos y puede conducir al diseño de intervenciones más poderosas (Irwin, 2017: 168).

Luego de realizar un análisis del estado actual de los circuitos de producción y consumo de una marca de moda rápida y los impactos que se generan, se considera que los principales puntos sobre los que se busca crear mejoras con esta propuesta, son la percepción de los consumidores sobre la duración de la vida útil de las prendas y el poder de influencia que tienen sus elecciones sobre el funcionamiento de la industria de la moda e indumentaria, ya que en la actualidad, los consumidores cumplen un rol relativamente pasivo frente a la verticalidad de la moda, aceptando tendencias que la mayoría de las veces son impuestas por las marcas dominantes.

La moda y las experiencias de consumo de fórmula pueden ser más fáciles de manufacturar para las marcas, pero su efecto típicamente es de apaciguar a los consumidores y de limitar sus expectativas. La falta de elecciones erosiona nuestra individualidad y opaca nuestra imaginación, limitando nuestra confianza acerca de lo que podría ser la vestimenta, mientras que los productores se presentan como cerrados o completos, con un estatus prácticamente intocable (Fletcher, 2014: 223).

Sin embargo, si se comienza a educar a los consumidores sobre las alternativas de uso que pueden darle a sus prendas para extender su vida útil y realmente apropiarse de los modos de uso de su indumentaria, se podrá romper con la verticalidad anteriormente nombrada. De esta manera, la propuesta de intervención desarrollada para esta investigación será la de crear un colectivo de diseñadores de moda e indumentaria que trabajen con las metodologías del Upcycling de reparar y reutilizar prendas y textiles descartados por la moda rápida, colaborando con los consumidores para hacerlos parte de los procesos de creación y diseño. Esto se vincula con lo que postula Fletcher sobre el diseño participativo o colaborativo, donde "aquellos que usan un producto tienen el derecho de determinar cómo se diseña, ya que la calidad del diseño aumenta cuando los Stakeholders son incluidos en el proceso del diseño" (2014: 228), donde los diseñadores de moda e indumentaria podrán proponerle a los usuarios la implementación de distintas técnicas del Upcycling para prolongar el ciclo de vida de sus prendas. Esto servirá no sólo para trabajar sobre los aspectos materiales, al poder rescatar prendas rotas o desgastadas en lugar de desecharlas, sino que también ayuda a combatir la obsolescencia percibida, que se vincula con la idea de novedad y renovación a través de la vestimenta. 
En conjunto con la labor de diseñadores gráficos quienes podrán crear material de apoyo visual y campañas de visualización, se buscará informar a los individuos acerca del impacto que tienen sus decisiones de consumo, para empoderarlos a tomar un rol activo frente a su relación con la moda y así comenzar a participar de circuitos de circularidad. Este colectivo de diseñadores, tanto de moda e indumentaria como del diseño gráfico, podrá prestar sus servicios para trabajar con marcas de la moda rápida para comenzar a generar cambios en sus procesos productivos al proponer alternativas de uso para extender el ciclo de vida de las prendas que desarrollan y combatir la generación de residuos sólidos textiles, así como también educar a los actores dentro de la marca sobre los impactos que tienen sus decisiones en el ambiente y en la vida de los individuos. Extender los ciclos de vida de las prendas genera un acercamiento a lo que se conoce como slow fashion o moda lenta.

Slow fashion no es solo una descripción de velocidad, sino también una cosmovisión diferente que promueve una variedad y multiplicidad de modos de producción y consumo de la moda y que celebra el placer y la significancia cultural de la moda dentro de los limites biofísicos. Se apoya sobre un cambio en las relaciones de poder entre los creadores de la moda y los usuarios en comparación con la moda consumista. Profesa un sentido de mayor conciencia sobre el proceso de diseño y sus impactos sobre los flujos de recursos, los trabajadores, las comunidades, y los ecosistemas. Le coloca precios más elevados a las prendas para dar cuenta de los verdaderos costos sociales y ecológicos y, como modelo de producción, ofrece una alternativa radical a la moda estandarizada de alto volumen (Fletcher, 2014: 204).

Se propone, además, realizar talleres de capacitación con los trabajadores que elaboran los procesos de corte y confección de las prendas dentro de los talleres textiles sobre las distintas técnicas del Upcycling. Educar, informar, y capacitar de esta forma a los trabajadores les dará más herramientas para poder generar ingresos adicionales, ofreciendo a los usuarios servicios de mantenimiento, reparación y personalización de las prendas para no depender exclusivamente del salario brindado que se calcula únicamente por cada prenda que confeccionan para la marca.

Existe un gran número de iniciativas lideradas por diseñadores y productores focalizadas en el manejo de desechos textiles, que construyen experiencia con la implementación de estrategias como el re-uso y reciclado, y emergen de un espacio de la moda como práctica social y material. Articulan las identidades individuales y las estructuras sociales de los desechos en la indumentaria y los textiles, impartiéndoles aceptabilidad social, creatividad, estatus e incluso, lujo (Fletcher, 2014: 116).

Sabiendo de qué se trata la propuesta de esta investigación y sus posibles aplicaciones dentro del sistema, se analiza sobre cuáles de los puntos de apalancamiento de Meadows (1997) podrá trabajar, y de qué manera se desenvuelve esta intervención diseñada dentro de la visión de futuro sostenible para la industria de la moda e indumentaria. Nuevamente se utilizará 
la lente del Diseño para la Transición y las herramientas que provee, para explicar de qué manera los resultados esperados de la propuesta servirían para comenzar a transformar la moda e indumentaria en una industria con perspectivas de sostenibilidad ética y ambiental.

- En primer lugar, se considera que influye sobre la fuerza de retroalimentación positiva, ya que al informar y concientizar a los individuos sobre los impactos sociales y ambientales de sus decisiones de consumo, se generará mayor demanda de alternativas a la moda rápida con tendencia sostenible.

- En segundo lugar, la propuesta trabaja sobre los flujos de información, que se dan entre la marca, los talleres textiles, los consumidores y el colectivo de diseñadores, ya que "el poder de la información para generar cambios hacia la sostenibilidad se observa en la puja hacia la transparencia absoluta con la esperanza de que la franqueza lleve a prácticas más sostenibles" (Fletcher, 2014: 79).

Debido a que todas las personas operan de diferentes modos, para poder encaminarse hacia los cambios sociotécnicos a los que apunta el Diseño para la transición, es necesario que todos los miembros de la sociedad compartan una ideología en común fundamentada en la sostenibilidad ética y ambiental. Es necesario, además, descartar el modo de pensar lineal y reduccionista, dejando de pensar en los objetos y pasando a poner a los sujetos en primer lugar (Vinlove, 2020: 158).

- Por otro lado, se busca influenciar las reglas del sistema, al impulsar relaciones laborales más justas para los trabajadores textiles con la implementación de talleres de capacitación, así como también la reutilización de las prendas en desuso a través del Upcycling para disminuir los impactos en los recursos naturales: "Las reglas del sistema definen el alcance $y$ los limites de la industria textil y de la moda y determinan a quienes beneficia" (Fletcher, 2014: 80). La auto-regulación del sistema sería otro punto de intervención, al proponer el trabajo colaborativo entre los diseñadores de moda e indumentaria y los diseñadores gráficos así como también entre ellos, como colectivo de diseñadores, y las fuerzas dominantes dentro de la industria: "Para promover la auto-regulación se debe promover la diversidad, una visión pluralista, y la construcción de un rango de potenciales soluciones e ideas lo más amplia posible" (Fletcher, 2014: 82).

- También, se buscaría intervenir sobre las reglas del sistema, para influenciar los propósitos de la industria al incorporar estrategias de economía circular como el Upcycling, para modificar los productos y los impactos resultantes. Estos esfuerzos por tomar distancia del estado actual de la industria, que funciona bajo los principios de economía lineal, cambiaría las metas del sistema con la finalidad de promover la sostenibilidad social y ambiental.

- Por último, posicionando al diseñador como agente de cambio, se buscaría modificar los paradigmas que han permitido sostener a la industria de la moda rápida durante las últimas décadas, ya que: 
(...) las mentalidades aceptadas y establecidas alrededor de los paradigmas son el origen de los sistemas y sientan las bases de lo que hacemos pero a menudo contienen anomalías que distorsionan nuestra experiencia y comprensión del mundo. Si influenciamos al nivel de un paradigma, el sistema podrá transformarse totalmente, y si se aprovecha su poder en función de la sostenibilidad, probablemente seguirían cambios culturales y ecológicos substanciales (Fletcher, 2014: 85).

En el caso particular de la industria de la moda e indumentaria, un cambio de paradigma implicaría la posibilidad de transformar los circuitos de producción y consumo, donde el bienestar de las personas y del ambiente serían la primera prioridad, y donde la vestimenta representaría las identidades de los individuos con absoluta libertad creativa, sin la imposición de tendencias sofocantes ni estereotipos limitantes que dicten reglas arbitrariamente para ejercer control sobre las personas y así crear necesidades ficticias para fomentar el consumo de manera excesiva para generar riqueza desmedida para unos pocos.

Habiendo estudiado de qué manera la propuesta elaborada interviene dentro del sistema y algunos de los posibles escenarios resultantes, se pasa a mencionar su impacto en las distintas escalas de estilo de vida (Ver Figura 5). Aquí, se "sitúan visiones societarias en el largo plazo, las estrategias de negocios en el mediano plazo, y el desarrollo de productos en el corto plazo" (Gaziulusoy, 2017: 73). Entonces, en el contexto inmediato, son impactados los productores (incluyendo a la marca especifica analizada y los talleres textiles de corte y confección), los consumidores de la categoría elegida en esta investigación y los diseñadores, considerados los principales Stakeholders con los que se trabaja en el desarrollo de la propuesta. Dentro del contexto intermedio (visto un poco más ampliamente), se observan impactos en la industria local y los espacios públicos físicos y virtuales (redes sociales). Extendiendo aún más el alcance de la propuesta, se observa el impacto en el contexto amplio, donde se sitúan los valores, las normas y la cultura misma que influencian a las instituciones, las ciudades, los estados o provincias, y hasta a países enteros (todas las partes que conforman un sistema). 


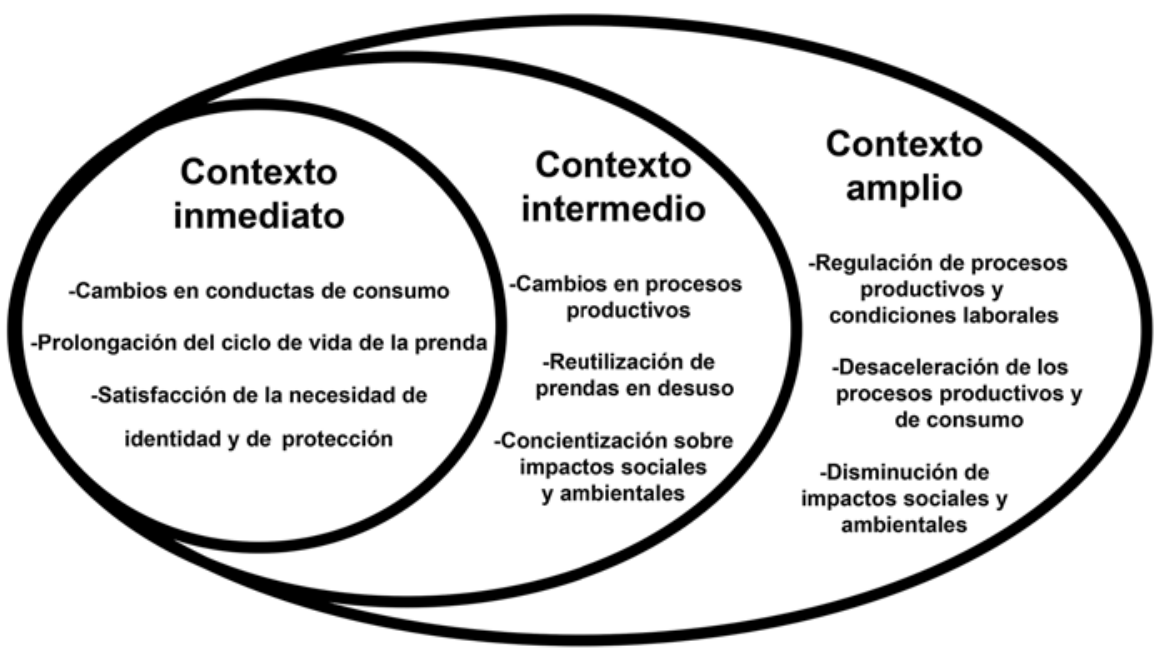

Figura 5. Escalas de los estilos de vida basadas en la posible intervención definida en el Backcasting (Fuente: Alexandra Vinlove).

Luego de situar la propuesta en las escalas de estilos de vida, se la estudia a través de la utilización de otra de las herramientas utilizada en el Diseño para la Transición, conocida como la matriz de Social Design Pathways, propuesta por el Instituto Winterhouse en 2013. Irwin, Kossoff y Tonkinwise (2020) hacen referencia a la utilización de esta herramienta para responder a problemas complejos, como los que se desarrollan en la industria de la moda rápida, ya que para comenzar a desenmarañar estos entramados, resulta necesario que los diseñadores puedan trabajar de manera colaborativa y participativa con profesionales y expertos de otras disciplinas. Explica que esta matriz se puede utilizar para distintos propósitos, entre ellos de visionar y mapear intervenciones dentro de múltiples niveles de escala para lograr mayor impacto, para guiar la investigación y el diseño, y para estudiar los resultados de una intervención. Irwin (2017) argumenta que para poder observar cambios constatables en un problema perverso con alcance sistémico, se deben implementar las soluciones propuestas en todas las áreas de la matriz a través de largos períodos de tiempo. Además, debido a la naturaleza interrelacionada y siempre cambiante de los problemas perversos, debe observarse la respuesta del sistema frente a la intervención puesta en marcha para luego recontextualizar el presente, realizar ajustes donde sea necesario, y continuar operando... y así sucesivamente.

Los modelos de Social Design Pathways, son más una herramienta para tomar una decisión acerca del punto de entrada apropiado para la escala de cambio 
que se ajuste a los recursos y las condiciones actuales. Combina los niveles de compromiso o escalas de diseño con la naturaleza de la expertise involucrada, desde específico al diseño, pasando por las colaboraciones interdisciplinarias, hasta la formación de redes. La labor de un Diseñador para la Transición con impacto colectivo ocurre en un punto de apalancamiento local pero dentro de una red cosmopolita de intervenciones multi-nivel llevadas a cabo por otros (Tonkinwise, 2017: 93).

Así, se considera que, al utilizar las habilidades específicas de los diseñadores, en este caso de moda e indumentaria, para trabajar en conjunto con equipos de otras disciplinas e incorporando la experiencia de distintos grupos sociales en las distintas escalas de compromiso de la matriz Winterhouse (2013) se pueden catalizar los cambios sociotécnicos necesarios para transicionar hacia las visiones de futuro sostenible (Ver Figura 6) donde la aplicación exitosa de estos cambios, dependerá del "desarrollo de capacidades cognitivas, críticas, perceptivas, y sociales para diseñar estilos de vida ecológica [y socialmente] sostenibles" (Boehnert, 2017: 138).

\begin{tabular}{|c|c|c|c|}
\hline Transformation & $\begin{array}{l}\text { Reducción de prendas } \\
\text { desechadas por } \\
\text { temporada }\end{array}$ & $\begin{array}{c}\text { Capacitar a los } \\
\text { trabajadores de talleres } \\
\text { textiles para generar } \\
\text { ingresos alternativos y } \\
\text { concientizar sobre sus } \\
\text { derechos }\end{array}$ & $\begin{array}{c}\text { Nuevo modelo de negocio } \\
\text { de la moda e } \\
\text { indumentaria basado en } \\
\text { el Upcycling como } \\
\text { estrategia de economia } \\
\text { circular }\end{array}$ \\
\hline Innovation & $\begin{array}{l}\text { Presentar metodologias } \\
\text { del Upcycling para } \\
\text { prolongar el ciclo de vida } \\
\text { de las prendas }\end{array}$ & $\begin{array}{l}\text { Ofrecer servicios de } \\
\text { capacitación en marcas de } \\
\text { la moda rápida para } \\
\text { rediseñar los ciclos de } \\
\text { producción con perspectiva } \\
\text { sostenible }\end{array}$ & $\begin{array}{l}\text { Desaceleración de los } \\
\text { ciclos de producción y } \\
\text { consumo en la industria } \\
\text { de la moda e } \\
\text { indumentaria }\end{array}$ \\
\hline \multirow[t]{2}{*}{ Intervention } & $\begin{array}{l}\text { Creación de un colectivo } \\
\text { de diseñadores que } \\
\text { trabajen sobre diseño } \\
\text { sostenible }\end{array}$ & $\begin{array}{l}\text { Creación de piezas } \\
\text { gráficas que ayuden a } \\
\text { informar sobre los } \\
\text { beneficios del Upcycling } \\
\text { como estrategia de } \\
\text { economia circular y para } \\
\text { satisfacer necesidades }\end{array}$ & $\begin{array}{l}\text { Generación de conciencia } \\
\text { sobre el impacto social y } \\
\text { ambiental de los } \\
\text { procesos productivos y } \\
\text { las elecciones de } \\
\text { consumo }\end{array}$ \\
\hline & Designer & Team & Group/Partnership \\
\hline
\end{tabular}

Figura 6. Esquema de Pathways of Social Design, Instituto Winterhouse, basado en el visionado propuesto en el backcasting (Fuente: Alexandra Vinlove). 


\section{Conclusión}

A modo de conclusión, considerando que la labor del diseñador de moda e indumentaria se encuentra en constante cambio y evolución y requiere de gran conciencia y responsabilidad, se resalta la importancia de utilizar la lente del Diseño para la Transición para poder desarrollar prácticas que contemplen e intenten reducir los impactos que la industria causa sobre los recursos naturales y sobre el bienestar de los individuos. Luego de realizar el análisis situacional de la marca elegida y su relación con un determinado grupo de consumidores, tomada solo como ejemplo para contextualizar los objetivos de esta investigación, se considera que la propuesta planteada tiene la capacidad potencial de intervenir eficazmente dentro del sistema de problema perverso, para transicionar hacia un futuro de moda e indumentaria sostenibles. Aquí, los diseñadores se posicionan como agentes de cambio ya que según Fletcher, se debe situar al diseño de moda e indumentaria dentro de un

(...) marco de referencia moral más amplio y sistemas de comprensión más profundos. Esto nos permitirá ver y sentir a la sostenibilidad en la moda e indumentaria como un proceso dinámico de acciones humanas y sus efectos materiales asociados. El resultado es la valoración de contribuciones materiales y técnicas pero también el reconocimiento de que estas serán más efectivas cuando estén apoyadas por principios morales generales. La sostenibilidad en moda e indumentaria es una invitación para crear riqueza y capital cultural de todo tipo de formas, incluyendo por fuera del sistema industrial [tradicional] como parte del camino hacia la implementación de nuevos modelos de negocio creados para desvincular la lucratividad del consumo de moda e indumentaria (Fletcher, 2014: 243).

Desde una valoración más personal, aún queda mucho camino por recorrer pero dando los primeros pasos dentro de la sostenibilidad en la moda e indumentaria -incluso empezando por crear mejoras en la materialidad- es como se podrán comenzar a impulsar los cambios necesarios para convertir la industria en un espacio de creatividad, inclusión y aceptación de las diversidades, empatía y consciencia acerca de los límites de la biodiversidad.

\section{Endnotes}

1. Esta búsqueda se desarrolla para poder ampliar y reorientar la investigación que la autora llevó a cabo en su artículo publicado en el Cuaderno N.105 del Centro de Estudios en Diseño y Comunicación de la Universidad de Palermo, con la finalidad de intervenir en los circuitos de la moda desde su rol como profesional del Diseño de Moda e Indumentaria para guiar la Gestión de Diseño hacia la promoción de algunos de los Objetivos de Desarrollo Sostenible (ONU), relacionados con (a) la sostenibilidad social: con la igual- 
dad de género, la reducción de las desigualdades, el trabajo en condiciones decentes, el consumo responsable; y en lo vinculado con (b) la sostenibilidad ambiental: se busca la revalorización del diseñador como productor responsable, para generar el saneamiento del agua, la utilización de energías renovables y no contaminantes, la acción por el clima y los ecosistemas terrestres, la vida submarina y ciudades sostenibles (Vinlove, 2020: 149).

\section{Referencias Bibliográficas}

Bauman, Z. (2000). Modernidad líquida. Buenos Aires: Fondo de Cultura Económica de Argentina, S.A.

Barreiro, A. (2004). La construcción social del cuerpo en las sociedades contemporáneas. La Coruña: Universidad de La Coruña.

Bhardwaj, V. y Fairhurst, A. (2010). Fast fashion: Response to changes in the fashion industry. Oxfordshire: Routledge \& CRC Press.

Boehnert, J. (2017). Transition Design and Ecological Throught. Cuaderno del Centro de Estudios en Diseño y Comunicación N.73. Buenos Aires: Universidad de Palermo.

Cline, E. (2014). Moda desechable: El escandaloso costo de la ropa barata. México D.F.: Ediciones Culturales Paidós.

Croci, P. y Vitale, A. (2012). Los cuerpos dóciles: hacia un tratado sobre la moda. (3era edición). Buenos Aires: La Marca Editorial.

D’Ortenzio, V. (2020). Hiperconectados. La señalética y su impacto en los consensos sociales. Cuaderno del Centro de Estudios en Diseño y Comunicación N.105. Buenos Aires: Universidad de Palermo.

Di Bella, D. (2020). Problematizar el Diseño para comprender su complejidad. $4^{\circ}$ Proyecto de la Línea de Investigación No4 Diseño en Perspectiva (CMU-UP). Cuaderno del Centro de Estudios en Diseño y Comunicación N.105. Buenos Aires: Universidad de Palermo.

Di Bella, D. (2018). Impacto de la Experiencia Diseño en Perspectiva. Cuaderno del Centro de Estudios en Diseño y Comunicación N.80. Buenos Aires: Universidad de Palermo.

Di Bella, D. (2017). Prólogo de la Primera Sección. Cuaderno del Centro de Estudios en Diseño y Comunicación N.73. Buenos Aires: Universidad de Palermo.

Entwistle, J. (2002). El cuerpo y la moda: una visión sociológica. Barcelona: Editorial Paidós.

Fletcher, K. (2014). Sustainable Fashion and Textiles: Design Journeys. Oxfordshire: Routledge \& CRC Press.

Gaziulusoy, A. (2017). Postcards From "the Edge": Toward Futures of Design for Sustainability Transitions. Cuaderno del Centro de Estudios en Diseño y Comunicación N.73. Buenos Aires: Universidad de Palermo.

Hughes, A. (2018). How Fashion Nova Won the Internet. Disponible en https://wwd.com/ fashion-news/fashion-features/inside-fashion-nova-cardi-b-1202595964/. Recuperado el 19/11/2020.

Irwin, T. (2017). The Emerging Transition Design Approach. Cuaderno del Centro de Estudios en Diseño y Comunicación N.73. Buenos Aires: Universidad de Palermo. 
Irwin, T.; Tonkinwise, C. y Kossoff, G. (2020). Transition Design: An Educational Framework for Advancing the Study of Design of Sustainable Transitions. Cuaderno del Centro de Estudios en Diseño y Comunicación N.105. Buenos Aires: Universidad de Palermo.

Kitroeff, N. (2019). Fashion Nova's Secret: Underpaid Workers in Los Angeles Factories. Disponible en https://www.nytimes.com/2019/12/16/business/fashion-nova-underpaidworkers.html?auth=login-google. Recuperado el 19/11/2020.

Kossoff, G. (2017). Cosmopolitan Localism: The Planetary Networking of Everyday Life in Place. Cuaderno del Centro de Estudios en Diseño y Comunicación N.73. Buenos Aires: Universidad de Palermo.

Lockton, D. y Candy, S. (2017). A Vocabulary for Visions in Designing for Transitions. Cuaderno del Centro de Estudios en Diseño y Comunicación N.73. Buenos Aires: Universidad de Palermo.

Meadows, D.; Meadows, D. y Randers, J. (2006). Limits to Growth: The 30-Year Update. Londres: Eartscan.

Nguyen, T. (2020). Fast Fashion, explained. Disponible en https://www.vox.com/thegoods/2020/2/3/21080364/fast-fashion-h-and-m-zara. Recuperado el 30/10/2020.

Pampliega de Quiroga A. y Pichon-Riviere E. (1985). Psicología de la vida cotidiana. Buenos Aires: Editorial Nueva Visión SAIC.

Tonkinwise, C. (2017). Design's (Dis)orders: Mediating Systems-Level Transition Design. Cuaderno del Centro de Estudios en Diseño y Comunicación N.73. Buenos Aires: Universidad de Palermo.

Veneziani, M. (2012). Moda, economía y sociedad. Buenos Aires: Editorial Nobuko.

Vinlove, A. (2020). Cuerpos que importan. Reflexionando sobre el estado actual de la industria del denim y las problemáticas que contiene. Cuaderno del Centro de Estudios en Diseño y Comunicación N.105. Buenos Aires: Universidad de Palermo.

Vizcarra, F. y Olvalle, L. (2011). Ciberculturas: el estado actual de la investigación y análisis. Santiago: Pontificia Universidad Católica de Chile.

Zambrini, L. (2008). Cuerpos, indumentarias y expresiones de género: el caso de las travestis en la Ciudad de Buenos Aires. En Figari, C., Jones, D. y Pecheny, M. (Comp.), (2008). Todo sexo es político. Estudios sobre sexualidades en Argentina. Buenos Aires: Libros del Zorzal.

S/D. Donella Meadows archives. Leverage Points: Places to intervene in a System. Disponible en http://donellameadows.org/archives/leverage-points-places-to-intervene-in-a-system/ Recuperado el 14/11/2020.

S/D. Ethical Fashion Report. Disponible en https://baptistworldaid.org.au/resources/ethical -fashion-report/. Recuperado el 15/10/2020.

S/D. Fashion Checker. Disponible en https://fashionchecker.org/. Recuperado el 15/10/2020.

S/D. Fashion Transparency Index 2020. Disponible en https://www.fashionrevolution.org/ about/transparency/. Recuperado el 30/10/2020.

S/D. Cardi B. Disponible en https://www.instagram.com/iamcardib/. Recuperado el $18 / 10 / 2020$.

S/D. Fashion Nova. Disponible en https://www.instagram.com/fashionnova/. Recuperado el 17/10/2020.

S/D. Fashion Nova Curve. Disponible en https://www.instagram.com/FashionNovaCURVE/. Recuperado el 17/10/2020. 
S/D. Fashion Nova Men. Disponible en https://www.instagram.com/FashionNovaMEN/. Recuperado el 17/10/2020.

S/D. Winterhouse Institute Social Design Pathways. Disponible en http://www.winterhouse institute.org/pathways Recuperado el 19/11/2020.

\section{Bibliografía}

Bauman, Z. (2000). Modernidad líquida. Buenos Aires: Fondo de Cultura Económica de Argentina, S.A.

Barreiro, A. (2004). La construcción social del cuerpo en las sociedades contemporáneas. La Coruña: Universidad de La Coruña.

Bhardwaj, V. y Fairhurst, A. (2010). Fast fashion: Response to changes in the fashion industry. Oxfordshire: Routledge \& CRC Press.

Boehnert, J. (2017). Transition Design and Ecological Throught. Cuaderno del Centro de Estudios en Diseño y Comunicación N.73. Buenos Aires: Universidad de Palermo.

Butler, J. (2002). Cuerpos que importan: sobre los limites materiales y discursivos del sexo. Buenos Aires: Editorial Paidós SAICF.

Butler, J. (2007). El género en disputa. El feminismo y la subversión de la identidad. Barcelona: Ediciones Paidós Ibérica S.A.

Cline, E. (2014). Moda desechable: El escandaloso costo de la ropa barata. México D.F.: Ediciones Culturales Paidós.

Croci, P. y Vitale, A. (2012). Los cuerpos dóciles: hacia un tratado sobre la moda. (3era edición). Buenos Aires: La Marca Editorial.

D’Ortenzio, V. (2020). Hiperconectados. La señalética y su impacto en los consensos sociales. Cuaderno del Centro de Estudios en Diseño y Comunicación N.105. Buenos Aires: Universidad de Palermo.

Darmo, J. (2020). 20 Hard Facts About Fast Fashion. Disponible en https://goodonyou.eco/ fast-fashion-facts/. Recuperado el 30/10/2020

Di Bella, D. (2020). Problematizar el Diseño para comprender su complejidad. $4^{\circ}$ Proyecto de la Línea de Investigación No4 Diseño en Perspectiva (CMU-UP). Cuaderno del Centro de Estudios en Diseño y Comunicación N.105. Buenos Aires: Universidad de Palermo.

Di Bella, D. (2018). Impacto de la Experiencia Diseño en Perspectiva. Cuaderno del Centro de Estudios en Diseño y Comunicación N.80. Buenos Aires: Universidad de Palermo.

Di Bella, D. (2017). Prólogo de la Primera Sección. Cuaderno del Centro de Estudios en Diseño y Comunicación N.73. Buenos Aires: Universidad de Palermo.

Entwistle, J. (2002). El cuerpo y la moda: una visión sociológica. Barcelona: Editorial Paidós.

Fletcher, K. (2014). Sustainable Fashion and Textiles: Design Journeys. Oxfordshire: Routledge \& CRC Press.

Gaziulusoy, A. (2017). Postcards From "the Edge": Toward Futures of Design for Sustainability Transitions. Cuaderno del Centro de Estudios en Diseño y Comunicación N.73. Buenos Aires: Universidad de Palermo. 
Hughes, A. (2018). How Fashion Nova Won the Internet. Disponible en https://wwd.com/ fashion-news/fashion-features/inside-fashion-nova-cardi-b-1202595964/. Recuperado el 19/11/2020.

Irwin, T. (2017). The Emerging Transition Design Approach. Cuaderno del Centro de Estudios en Diseño y Comunicación N.73. Buenos Aires: Universidad de Palermo.

Irwin, T. (2012). Wicked Problems and the Relationship Triad. Edinburgo: Floris Books.

Irwin, T.; Tonkinwise, C. y Kossoff, G. (2020). Transition Design: An Educational Framework for Advancing the Study of Design of Sustainable Transitions. Cuaderno del Centro de Estudios en Diseño y Comunicación N.105. Buenos Aires: Universidad de Palermo.

Julier, G. (2000). The culture of design. Londres: Sage Publications Ltd.

Julier, G. (2006). From visual culture to design culture. Cambridge: Massachusetts Institute of Technology.

Kitroeff, N. (2019). Fashion Nova's Secret: Underpaid Workers in Los Angeles Factories. Disponible en https://www.nytimes.com/2019/12/16/business/fashion-nova-underpaid -workers.html?auth=login-google. Recuperado el 19/11/2020.

Kossoff, G. (2017). Cosmopolitan Localism: The Planetary Networking of Everyday Life in Place. Cuaderno del Centro de Estudios en Diseño y Comunicación N.73. Buenos Aires: Universidad de Palermo.

Lockton, D. y Candy, S. (2017). A Vocabulary for Visions in Designing for Transitions. Cuaderno del Centro de Estudios en Diseño y Comunicación N.73. Buenos Aires: Universidad de Palermo.

Max-Neef, M.; Elizalde, A, y Hopenhayn, M. (1991). Human Scale Development. Lanham: The Apex Press.

Meadows, D.; Meadows, D. y Randers, J. (2006). Limits to Growth: The 30-Year Update. Londres: Eartscan.

Nguyen, T. (2020). Fast Fashion, explained. Disponible en https://www.vox.com/thegoods/2020/2/3/21080364/fast-fashion-h-and-m-zara. Recuperado el 30/10/2020.

Oittana, L. (2013). La desaparición de lo real o el éxtasis de la comunicación. Rosario: Universidad Nacional de Rosario.

Pampliega de Quiroga, A. y Pichon-Riviere, E. (1985). Psicología de la vida cotidiana. Buenos Aires: Editorial Nueva Visión SAIC.

Rittel, H. y Webber, M. (1973). Dilemmas in a General Theory of Planning. Amsterdam: Elsevier Scientific Publishing Company.

Tonkinwise, C. (2017). Design's (Dis)orders: Mediating Systems-Level Transition Design. Cuaderno del Centro de Estudios en Diseño y Comunicación N.73. Buenos Aires: Universidad de Palermo.

Veneziani, M. (2012). Moda, economía y sociedad. Buenos Aires: Editorial Nobuko.

Vinlove, A. (2020). Cuerpos que importan. Reflexionando sobre el estado actual de la industria del denim y las problemáticas que contiene. Cuaderno del Centro de Estudios en Diseño y Comunicación N.105. Buenos Aires: Universidad de Palermo.

Vizcarra, F. (2002). Premisas y conceptos básicos en la sociología de Pierre Bourdieu. Colima: Universidad de Colima.

Vizcarra, F. y Olvalle, L. (2011). Ciberculturas: el estado actual de la investigación y análisis. Santiago: Pontificia Universidad Católica de Chile. 
Zambrini, L. (2008). Cuerpos, indumentarias y expresiones de género: el caso de las travestis en la Ciudad de Buenos Aires. En Figari, C., Jones, D. y Pecheny, M. (Comp.), (2008). Todo sexo es político. Estudios sobre sexualidades en Argentina. Buenos Aires: Libros del Zorzal.

S/D. Donella Meadows archives. Leverage Points: Places to intervene in a System. Disponible en http://donellameadows.org/archives/leverage-points-places-to-intervene-in-a-system/ Recuperado el 14/11/2020.

S/D. Cardi B. Disponible en https://www.instagram.com/iamcardib/. Recuperado el $18 / 10 / 2020$.

S/D. Ethical Fashion Report. Disponible en https://baptistworldaid.org.au/resources/ethicalfashion-report/. Recuperado el 15/10/2020.

S/D. Fashion Checker. Disponible en https://fashionchecker.org/. Recuperado el 15/10/2020.

S/D. Fashion Transparency Index 2020. Disponible en https://www.fashionrevolution.org/ about/transparency/. Recuperado el 30/10/2020.

S/D. Fashion Nova. Disponible en https://www.instagram.com/fashionnova/. Recuperado el 17/10/2020.

S/D. Fashion Nova Curve. Disponible en https://www.instagram.com/FashionNovaCURVE/. Recuperado el 17/10/2020.

S/D. Fashion Nova Men. Disponible en https://www.instagram.com/FashionNovaMEN/. Recuperado el 17/10/2020.

S/D. Winterhouse Institute Social Design Pathways. Disponible en http://www.winterhouseinstitute.org/pathways Recuperado el 19/11/2020.

Abstract: At present there is a growing search to incorporate sustainable practices into fashion and clothing design, generally placing the focus on materiality and production processes, from the use of fibers whose production has less environmental impact, to the optimization of processes washing, dyeing and finishing, as well as the implementation of recycling systems. This is because "materials are usually the starting point from which fashion can contribute to sustainability. They are items of value for farmers, designers, producers, consumers and recyclers" (Fletcher, 2014: 21). However, designing interventions focused solely on creating improvements in the garment production processes -even with the intention of using fewer resources and / or reducing their impact- is not enough to distance itself from the reductionist approach, making it impossible to establish a change in paradigm in the functioning of fashion as an industry and as a cultural agent. If the fashion industry is understood as a complex system, where multiple actors with different cultures, behaviors, interests and aspirations intervene, a wide range of perspectives can be incorporated in solving problems, in order to promote significant changes and enduring to guarantee the transition of the industry towards one with a sustainable perspective in the ethical and environmental aspects.

This article will analyze the methodologies of Upcycling as a circular economy strategy capable of intervening in the operation of traditional production and consumption circuits, in order to generate a change in the business model in the Fashion and Clothing Design 
industry for transition to a sustainable future. These techniques are considered to have the potential to generate bridges with sustainability practices, by encouraging an approach to the local and a sense of community, supported by the generation of identity and inclusion through the personalization and customization of clothing. In this approach, clothing linked to the list of needs and satisfiers by Max-Neef (1991) will be considered.

We will work on these points by mapping the Wicked Problem (Rittel and Webber, 1973) on programmed obsolescence in traditional production cycles, considering in the analysis and in a general way, applicable to any standard fast fashion brand and consumer behaviors associated with this type of products and market brands, based on the data query of a leading online sales brand of streetwear type clothing.

There is no need to mention the name of the brand in the survey, but the idea is that the data will serve to contextualize the problems that develop within the fashion industry and clothing in the present time, with a focus on the possible intervention within the industry, system through Upcycling repair and reuse methodologies. From this approach, a possible intervention linked to the points of leverage established by Donella Meadows (1997) and their impacts on lifestyles will be identified, situating them under the lens of the Design for the Transition (Irwin, Kossoff y Tonkinwise, 2015).

Keywords: Fashion and Clothing Design - Upcycling - Sustainable Fashion - Sustainability - Inclusiveness - Accessibility - Lifestyles - Design for Transition - Leverage points - Wicked Problem.

Resumo: Atualmente é crescente a busca pela incorporação de práticas sustentáveis ao design de moda e vestuário, geralmente com foco na materialidade e nos processos de produção, desde a utilização de fibras cuja produção tem menor impacto ambiental, até a otimização dos processos de lavagem, tingimento e acabamento, bem como implantação de sistemas de reciclagem. Isso porque "os materiais costumam ser o ponto de partida a partir do qual a moda pode contribuir para a sustentabilidade. São itens de valor para agricultores, designers, produtores, consumidores e recicladores" (Fletcher, 2014: 21). No entanto, conceber intervenções voltadas apenas para a melhoria dos processos de produção do vestuário -mesmo com o intuito de utilizar menos recursos e / ou reduzir o seu impacto- não é suficiente para se distanciar da abordagem reducionista, impossibilitando o estabelecimento de uma mudança de paradigma, no funcionamento da moda como indústria e como agente cultural. Se a indústria da moda for entendida como um sistema complexo, onde intervêm múltiplos atores com diferentes culturas, comportamentos, interesses e aspirações, será possível incorporar um amplo leque de perspectivas na resolução de problemas, de forma a promover mudanças significativas e duradouras para garantir a transição da indústria para uma perspectiva sustentável nos aspectos éticos e ambientais.

Este artigo irá analisar as metodologias do Upcycling como estratégia de economia circular capaz de intervir no funcionamento dos circuitos tradicionais de produção e consumo, de forma a gerar uma mudança no modelo de negócio da indústria de Design de Moda e Vestuário para a transição para um futuro sustentável. Considera-se que estas técnicas têm potencial para criar pontes com práticas de sustentabilidade, incentivando a aproximação 
ao local e o sentido de comunidade, apoiados na geração de identidade e inclusão através da personalização e customização do vestuário. Nessa abordagem, roupas vinculadas à lista de necessidades e satisfatórias de Max-Neef (1991) serão consideradas.

Trabalharemos nesses pontos mapeando o Wicked Problem (Rittel e Webber, 1973) sobre a obsolescência programada nos ciclos de produção tradicionais, considerando na análise e de forma geral, aplicável a qualquer marca de fast fashion padrão e comportamento do consumidor associado a este tipo de produtos e marcas de mercado, com base na consulta de dados de uma marca líder de vendas online de roupas do tipo streetwear.

Não é necessário citar o nome da marca em questão, pois a ideia é que seus dados sirvam para contextualizar os problemas que se desdobram dentro da indústria da moda e do vestuário hoje, focando na possível intervenção no sistema por meio das metodologias de Upcycling de reparo e reutilização. A partir dessa abordagem, será identificada uma possível intervenção relacionada aos pontos de alavancagem estabelecidos por Donella Meadows (1997) e seus impactos nos estilos de vida, colocando-a sob a ótica do Design for Transition (Irwin, Kossoff e Tonkinwise, 2015).

Palavras chave: Design de Moda e Vestuário - Upcycling - Moda Sustentável - Sustenta-bilidade - Inclusividade - Acessibilidade - Estilos de Vida - Design para Transição - Pontos de Ala-vancagem - Problema Malvado. 